\title{
CPNE3 interaction with RACK1 protects against myocardial ischemia/reperfusion injury
}

\author{
XIAOQUN ZHANG, XUE HAN and YANAN ZHANG \\ Cardiology Department One, Cangzhou Central Hospital, Cangzhou, Hebei 061001, P.R. China
}

Received December 30, 2020; Accepted August 26, 2021

DOI: $10.3892 /$ etm.2021.11051

\begin{abstract}
Copine 3 (CPNE3) and receptor for activated C kinase 1 (RACK1) have been determined to be risk factors for patients with acute myocardial ischemia/reperfusion (I/R). The present study aimed to evaluate the role of CPNE3 and its interaction with RACK1 in myocardial (I/R) injury. Reverse transcription-quantitative PCR (RT-qPCR) and western blotting were performed to detect CPNE3 and RACK1 expression levels in H9c2 cells before and after the transfection of CPNE3 overexpression plasmid or small interfering RNA-RACK1. Cell viability was detected using a Cell Counting Kit- 8 assay, and immunoprecipitation assays were performed to determine the interaction between CPNE3 and RACK1. A commercial kit was used to examine lactate dehydrogenase (LDH) levels. The expression levels of inflammatory cytokines were detected via RT-qPCR and western blotting. Cell apoptosis was assessed via TUNEL staining and western blotting. The results demonstrated that the expression levels of CPNE3 and RACK1 were decreased in hypoxia/reoxygenation (H/R)-induced $\mathrm{H} 9 \mathrm{c} 2$ cardiomyocytes, which was consistent with the expression levels observed in the myocardial I/R injury rat model. It was found that CPNE3 overexpression upregulated RACK1 expression, increased cell viability and suppressed the release of LDH in H/R-induced H9c2 cells. Furthermore, CPNE3 overexpression inhibited the release of inflammatory cytokines and decreased cell apoptosis in H/R-induced cardiomyocytes by activating RACK1 expression. The present study suggested that CPNE3 served an important role in preventing I/R injury by interacting with RACK1, providing novel insight into the prevention of myocardial I/R injury, as well as the treatment and care of patients with myocardial I/R.
\end{abstract}

Correspondence to: Dr Xiaoqun Zhang, Cardiology Department One, Cangzhou Central Hospital, 16 Xinhua Middle Road, Cangzhou, Hebei 061001, P.R. China

E-mail: xiaoqunz2020@163.com

Key words: myocardial ischemia/reperfusion injury, copine 3, receptor for activated $\mathrm{C}$ kinase 1 , hypoxia/reperfusion

\section{Introduction}

Myocardial ischemia/reperfusion (I/R) injury can occur after various types of cardiac surgery, including open heart surgery, coronary artery bypass grafting, coronary angioplasty and embolic surgery, and can result in serious clinical manifestations in numerous parts of the body, thus limiting the effectiveness of reperfusion treatment (1).

Copine 3 (CPNE3) has recently been identified as a risk factor for patients with acute myocardial I/R, as those with low expression levels of CPNE3 tend to be subject to acute myocardial infarction (2). However, at present, there is a lack of research into the mechanism of action of CPNE3 in myocardial I/R injury.

Receptor for activated C kinase 1 (RACK1) is a type of multifaceted scaffold protein that mediates activated protein kinase $\mathrm{C}$ translocation through the cytomembrane, and has been shown to be a participant in the regulation of several cardiovascular diseases, such as cardiac failure and myocardial infarction (3). A previous study reported that CPNE3 can interact with RACK1 in non-small cell lung cancer (NSCLC), serving an oncogenic role in metastasis (4). Currently, the therapeutic strategies available for patients with myocardial $\mathrm{I} / \mathrm{R}$ injury are limited to the alleviation of its clinical symptoms, such as medical intervention with mannitol to relieve the limb swelling caused by cellular edema (5). Therefore, identifying an effective strategy for the prevention of myocardial $\mathrm{I} / \mathrm{R}$ injury is important. The present study aimed to evaluate the potential protective mechanism underlying the interaction between CPNE3 and RACK1 in myocardial I/R injury. The results of the present study may facilitate the development of innovative and effective strategies for the clinical treatment of myocardial I/R injury.

\section{Materials and methods}

Animals and treatments. Sprague-Dawley rats ( $\mathrm{n}=7$ per group; male; age, 2-3 months, weight, 180-220 g) were purchased from the Experimental Animal Center of Cangzhou Central Hospital. Rats were maintained in a controlled environment at $25 \pm 3^{\circ} \mathrm{C}$ with $\sim 30 \%$ relative humidity, 12 -h light/dark cycles and ad libitum access to food and water. All animal procedures and experimental methods were approved by the Committee on the Ethics of Animal Experiments of Cangzhou Central Hospital. The animal maintenance and experiments complied 
with the guidelines drafted by the Animal Ethics Committee of Cangzhou Central Hospital.

Myocardial I/R was simulated in rats by performing coronary artery ligation, with myocardial ischemia for $1 \mathrm{~h}$ followed by reperfusion for 2, 4 and $12 \mathrm{~h}$ (6). Rats in the sham group were threaded without ligation. The control group did not receive ligation. After model establishment, the rats displayed lethargy and hypothermia without anesthesia. Subsequently, the rats were anesthetized by the intraperitoneal injection of $0.8 \%$ pentobarbital sodium $(40 \mathrm{mg} / \mathrm{kg}$ ) and then sacrificed by cervical dislocation. Death was verified by cessation of the heartbeat. Myocardial tissues of the rats were collected for subsequent experiments.

$H \& E$ staining. Myocardial tissue was fixed with $10 \%$ formalin for $24 \mathrm{~h}$ at room temperature, embedded in paraffin and then and were cut into $10-\mu \mathrm{m}$ thick sections, embedded in paraffin and frozen at $-80^{\circ} \mathrm{C}$ for storage. Subsequently, the tissue sections were collected onto microscope slides at room temperature. The slides were incubated with hematoxylin solution (Shanghai Aladdin Biochemical Technology Co., Ltd.) for $10 \mathrm{~min}$ at $37^{\circ} \mathrm{C}$, washed with running water and then incubated with eosin (Beyotime Institute of Biotechnology) for $3 \mathrm{~min}$ at $37^{\circ} \mathrm{C}$. The myocardial slices were treated with ethanol to achieve transparency at $37^{\circ} \mathrm{C}$. Images were captured using a light microscope camera (Keyence Corporation; magnification, x400). ImageJ software (version 146; National Institutes of Health) was used for quantitative analysis.

Tetrazolium chloride (TTC) staining. Cardiac tissue from rats was isolated and rapidly frozen at $-20^{\circ} \mathrm{C}$ for $\sim 20 \mathrm{~min}$. After sectioning (thickness, $1 \mathrm{~mm}$ ), the tissue slices were incubated in $2 \% \mathrm{TTC}$ at $37^{\circ} \mathrm{C}$ in the dark for $20 \mathrm{~min}$. Subsequently, the tissue sections were fixed in $4 \%$ paraformaldehyde for $24 \mathrm{~h}$. Images were captured using a light microscope camera (Keyence Corporation, magnification, $\mathrm{x} 400$ ). Images of the stained tissue sections were obtained and Image-Pro Plus software (version 6.0; Media Cybernetics, Inc.) was used for image analysis. Healthy brain tissue was stained red and infarcted areas were stained white.

Cell culture and treatments. H9c2 cardiomyocytes (EK-Bioscience) were obtained for the establishment of a cellular model of myocardial I/R injury. H9c2 cells were cultured in DMEM (Gibco; Thermo Fisher Scientific, Inc.) supplemented with 10\% FBS (Gibco; Thermo Fisher Scientific, Inc.), $100 \mathrm{U} / \mathrm{ml}$ penicillin and $100 \mathrm{mg} / \mathrm{ml}$ streptomycin in a humidified incubator containing 95\% air and 5\% $\mathrm{CO}_{2}$ at $37^{\circ} \mathrm{C}$. At $80 \%$ confluence, $0.05 \%$ trypsin was used for cell digestion. Subsequently, hypoxia was induced in $\mathrm{H} 9 \mathrm{c} 2$ cells for $6 \mathrm{~h}$, followed by reoxygenation for 2, 4 or $12 \mathrm{~h}$. Briefly, after cellular incubation in glucose-free DMEM at $37^{\circ} \mathrm{C}$ for $4 \mathrm{~h}, \mathrm{H} 9 \mathrm{c} 2$ cells were placed in a hypoxic incubator containing $1 \% \mathrm{O}_{2}, 94 \% \mathrm{~N}_{2}$ and $5 \% \mathrm{CO}_{2}$ at $37^{\circ} \mathrm{C}$ for $6 \mathrm{~h}$. Subsequently, glucose was added to the culture media until it normalized, which occurred after $6 \mathrm{~h}$ of hypoxia, but before reoxygenation. Then, the cells were incubated in a normal environment with $95 \%$ air and $5 \% \mathrm{CO}_{2}$ at $37^{\circ} \mathrm{C}$ for 2,4 or $12 \mathrm{~h}$ as previously described (6). H9c2 cells in the control group were cultured in DMEM supplemented with $10 \% \mathrm{FBS}, 100 \mathrm{U} / \mathrm{ml}$ penicillin and
$100 \mathrm{mg} / \mathrm{ml}$ streptomycin in a humidified incubator containing $95 \%$ air and $5 \% \mathrm{CO}_{2}$ at $37^{\circ} \mathrm{C}$ until the end of the experiment.

Reverse transcription-quantitative PCR (RT-qPCR). Total RNA was extracted from the myocardial tissues of rats and H9c2 cells using TRIzol ${ }^{\circledR}$ reagent (Invitrogen; Thermo Fisher Scientific, Inc.), according to the manufacturer's protocol. Briefly, the tissues and cells were lysed using $1 \mathrm{ml}$ TRIzol reagent at room temperature for $10 \mathrm{~min}$, followed by centrifugation at $300 \mathrm{xg}$ at $4^{\circ} \mathrm{C}$ for $20 \mathrm{~min}$ to obtain the supernatant. After precipitation using isopropanol, the supernatant was washed with $75 \%$ ethanol $(1 \mathrm{ml})$ at $4{ }^{\circ} \mathrm{C}$ for $5 \mathrm{~min}$ and the precipitates were dried. The quality of RNA extraction was determined using a spectrophotometer. Total RNA was reverse transcribed into cDNA using a PrimeScript RT reagent kit (Takara Bio, Inc.) according to the manufacturer's instructions. The expression levels of CPNE3, RACK1 and inflammatory cytokines were detected via qPCR using SYBR Premix EX Taq (Takara Bio, Inc.). The following thermocycling conditions were used for qPCR: $95^{\circ} \mathrm{C}$ for $10 \mathrm{~min}$; followed by 40 cycles of $95^{\circ} \mathrm{C}$ for $10 \mathrm{sec}$ and $60^{\circ} \mathrm{C}$ for $60 \mathrm{sec}$. mRNA expression levels were quantified using the $2^{-\Delta \Delta \mathrm{Cq}}$ method and normalized to the internal reference gene GAPDH (7). The sequences of the forward and reverse primers used for qPCR: TNF- $\alpha$ forward, 5'-GAAACACACGAGACGCTGAA-3' and reverse, 5'-GAAAGCCCATTGGAATCCTT-3'; IL-6 forward, 5'-TGATGGATGCTTCCAAACTG-3' and reverse, 5'-GAG CATTGGAAGTTGGGGTA-3'; IL-1 $\beta$ forward, 5'-AGCTTC AGGAAGGCAGTGTC-3' and reverse, 5'-TCAGACAGCACG AGGCATTT-3'; CPNE3 forward, 5'-GATGGCGTGATC ACAGACCTT-3' and reverse, 5'-GGCTTCCATTGTCAC CGTCTA-3'; RACK1 forward, 5'-GCCACCCCAGTGTAC CTCTTTG-3' and reverse, 5'-TCACCTGCCATACACGCA CCAA-3'; GAPDH forward, 5'-TGGCCTTCCGTGTTCCTA CC-3' and reverse, 5'-CGCCTGCTTCACCACCTTCT-3'.

Western blotting. Total protein was extracted from myocardial tissues and H9c2 cells using RIPA reagent (Protech Technology Enterprise Co., Ltd.). Protein concentrations were determined using a BCA kit (Abcam). Subsequently, $20 \mu \mathrm{g}$ proteins were separated via $10 \%$ SDS-PAGE and transferred to PVDF membranes. Following blocking with $5 \%$ non-fat milk for $2 \mathrm{~h}$ at room temperature, the membranes were incubated overnight at $4^{\circ} \mathrm{C}$ with primary antibodies targeted against: CPNE3 (1:1,000; cat. no. ab236606; Abcam), RACK1 (1:1,000; cat. no. ab129084; Abcam), phosphorylated (p)-NF-кB P65 (1:1,000; cat. no. ab183559; Abcam), cyclooxygenase 2 (Cox2; 1:1,000; cat. no. ab179800; Abcam), P65 (1:1,000; cat. no. ab32536; Abcam), Bax (1:1,000; cat. no. ab32503; Abcam), caspase-3 (1:1,000; cat. no. ab32351; Abcam), cleaved caspase-3 (1:1,000; cat. no. ab32042; Abcam), cleaved poly(ADP-ribose) polymerase (PARP; 1:1,000; cat. no. ab32064; Abcam), PARP (1:1,000; cat. no. ab191217; Abcam), Bcl-2 (1:1,000; cat. no. ab32124; Abcam) and GAPDH (1:1,000; cat. no. ab8245; Abcam). After washing with $0.05 \%$ TBS-Tween 20 (Shanghai Aladdin Biochemical Technology Co., Ltd.), the membranes were incubated with HRP-conjugated anti-mouse IgG (1:5,000; cat. no. 7076S; Cell Signaling Technology, Inc.) secondary antibodies for $2 \mathrm{~h}$ at room temperature. Subsequently, the membranes were placed 
in the dark for $1 \mathrm{~h}$ after the addition of color developing solution. The signals were detected using an enhanced chemiluminescence reagent (Cytiva). Protein expression was semi-quantified using Image Lab software (version 3.0; Bio-Rad Laboratories, Inc.) with GAPDH as the loading control.

Cell Counting Kit (CCK)-8. H9c2 cells were inoculated $\left(2 \times 10^{3}\right.$ cells/well) into a 96 -well plate. After corresponding treatments in the different groups of cells, $10 \mu \mathrm{l}$ sterile CCK-8 solution (Dojindo Molecular Technologies, Inc.) was added to each well for $2 \mathrm{~h}$. Cell viability was detected at a wavelength of $450 \mathrm{~nm}$ using a microplate reader (Bio-Rad Laboratories, Inc.) according to the manufacturer's instructions.

Cell transfection. Before $\mathrm{H} 9 \mathrm{c} 2$ cells were subjected to $\mathrm{H} / \mathrm{R}$ treatment, cells were inoculated $\left(1 \times 10^{6}\right.$ cells/well) into a six-well plate and cultured for $12 \mathrm{~h}$ at $37^{\circ} \mathrm{C}$. At $\sim 80 \%$ confluence, cells were transfected with $20 \mathrm{nM}$ overexpression (Ov)-CPNE3 plasmid, $20 \mathrm{nM} \mathrm{Ov-negative} \mathrm{control} \mathrm{(NC,} \mathrm{an}$ empty vector) plasmid, $20 \mathrm{nM}$ RACK1-small interfering (si) RNA or $20 \mathrm{nM}$ non-targeting siRNA-NC (all purchased from Shanghai GenePharma Co., Ltd.) using Lipofectamine ${ }^{\circledR} 2000$ (Invitrogen; Thermo Fisher Scientific, Inc.) at $37^{\circ} \mathrm{C}$ for $48 \mathrm{~h}$ according to the manufacturer's protocol. At $48 \mathrm{~h}$ post-transfection, transfection efficiencies were assessed via RT-qPCR and western blotting. The transfected sequences were as follows: si-RACK1, 5'-GACATCATCATGTGGAAGC-3'; and si-NC, 5'-GACCATCATCATGTGGAAGC-3'.

Immunoprecipitation (IP) assay. An immunoprecipitation kit (cat. no. ab206996; Abcam) was used to detect the interaction between CPNE3 and RACK1. Cells were harvested using IP lysis buffer and centrifuged at $>13,000 \mathrm{x}$ for $30 \mathrm{~min}$ at $4^{\circ} \mathrm{C}$. The resulting supernatants were then collected for use. Magnetic beads were dissolved in IP buffer (Abcam), after which antibodies including CPNE3 (1:1,000; cat. no. ab236606; Abcam), RACK1 (1:1,000; cat. no. ab129084; Abcam) and normal rabbit immunoglobulin $\mathrm{G}$ (negative control; cat. no. ab172730; 1:1,000; Abcam) were added to the magnetic beads for ligation ( $5 \mathrm{~g}$ for each reaction) overnight at $4^{\circ} \mathrm{C}$. The cells were then mixed with the antigenic antibody complex and incubated with Protein A/G Sepharose ${ }^{\circledR}$ for $2 \mathrm{~h}$. The antigen-antibody complex attached to Protein A/G Sepharose was eluted, incubated with $50 \mu \mathrm{l}$ elution solution for $5 \mathrm{~min}$ and then centrifuged at $1,000 \mathrm{x} \mathrm{g}$ for $5 \mathrm{~min}$ at $4^{\circ} \mathrm{C}$. The supernatants were collected and mixed. The $\mathrm{pH}$ of the protein samples was immediately adjusted to the physiological value. Lastly, the eluted samples were desalinized, which was followed by protein precipitation examination via western blotting according to the manufacturer's protocol.

Lactate dehydrogenase ( $(\mathrm{DH})$ activity assay. An LDH Cytotoxicity assay kit (cat. no. C0016; Beyotime Institute of Biotechnology) was used to determine the LDH level, which is an indicator for cytotoxic release, in H9c2 cells. Cells were inoculated into a 96-well plate to $80-90 \%$ confluence. After the different treatments in the respective groups, the plate was centrifuged at $400 \times \mathrm{g}$ for $5 \mathrm{~min} 4^{\circ} \mathrm{C}$. Subsequently, $150 \mu \mathrm{l}$ PBS-diluted LDH release reagent was added per well and the plate was shaken for thorough mixing. Following incubation for $1 \mathrm{~h}$, the culture plate was centrifuged at $400 \mathrm{xg}$ for $5 \mathrm{~min}$ $4^{\circ} \mathrm{C}$. Then, $120 \mu 1$ supernatant from each well was added to a new 96-well plate, followed by detection with LDH working solution. The absorbance was measured at a wavelength of $490 \mathrm{~nm}$ using a microplate reader.

TUNEL staining. A colorimetric TUNEL Apoptosis Assay kit (Beyotime Institute of Biotechnology) was used to observe $\mathrm{H} 9 \mathrm{c} 2$ cell apoptosis. Cells were fixed with Immunol Staining Fix Solution (Beyotime Institute of Biotechnology) for $30 \mathrm{~min}$ at $37^{\circ} \mathrm{C}$, followed by washing with PBS. Cells were then incubated with PBS containing 0.3\% Triton X-100 (Sigma-Aldrich; Merck $\mathrm{KGaA}$ ) at room temperature for $5 \mathrm{~min}$. After washing with PBS, TUNEL solution was added for $1 \mathrm{~h}$ at $37^{\circ} \mathrm{C}$. DAPI was then used to stain cells for $10 \mathrm{~min}$ at room temperature in the dark. Finally, five random fields of views were selected for analysis, in which H9c2 cell apoptosis was observed using glass coverslips with PBS as mounting medium. Images were captured using a regular optical microscope (magnification, $\mathrm{x} 200$ ). The number of apoptotic cells was calculated as follows: Mean proportion of positive cells/total number of cells in five fields of view per slide.

Data analysis. Statistical analyses were performed using GraphPad Prism software (version 8.0.1; GraphPad Software, Inc.). Data are presented as the mean \pm SD. One-way ANOVA followed by Tukey's post hoc test was used to analyze comparisons among multiple groups. $\mathrm{P}<0.05$ was considered to indicate a statistically significant difference. Each experiment was repeated three times.

\section{Results}

Decreased expression levels of CPNE3 and RACK1 in $I / R$-induced rat myocardial tissues. Pathological infiltration and the ischemic area of the myocardial tissues of I/R-induced rats were observed via $H \& E$ staining. Compared with the control group, the I/R-induced myocardial tissues displayed severe pathological infiltration and a significantly larger ischemic area (Fig. 1A and B). Additionally, the relative gene and protein expression levels of CPNE3 and RACK1 were detected via RT-qPCR and western blotting, respectively. CPNE3 and RACK1 expression levels were significantly lower compared with those in the control and sham groups exposed to I/R for 2, 4 and $12 \mathrm{~h}$ (Fig. 1C and D). The results demonstrated that the expression level of CPNE3 decreased with increasing reperfusion time. Moreover, although the expression level of RACK1 started to significantly rise from 4 to $12 \mathrm{~h}$ of $\mathrm{I} / \mathrm{R}$, it remained lower compared with that in the control group.

Decreased expression levels of CPNE3 and RACK1 in hypoxia/reoxygenation $(H / R)$-induced cardiomyocytes. Cell viability was detected after $\mathrm{H} / \mathrm{R}$ for 2,4 or $12 \mathrm{~h}$. The results demonstrated that the viability of $\mathrm{H} 9 \mathrm{c} 2$ cells was gradually decreased with increasing reoxygenation time (Fig. 2A). The western blotting (Fig. 2B and C) and RT-qPCR (Fig. 2D) results indicated decreased expression levels of CPNE3 and RACK1 in $\mathrm{H} / \mathrm{R}$-induced $\mathrm{H} 9 \mathrm{c} 2$ cells with increasing durations of $\mathrm{H} / \mathrm{R}$; however, RACK1 only increased between 4 and $12 \mathrm{~h}$ of H/R. Therefore, H/R for $4 \mathrm{~h}$ was selected for subsequent experiments. 
A

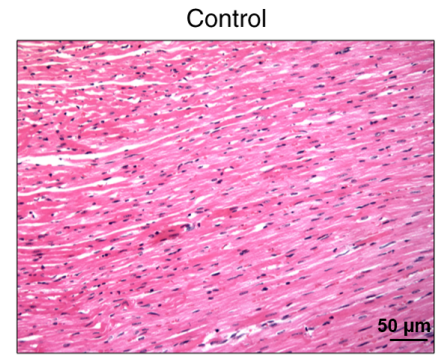

B

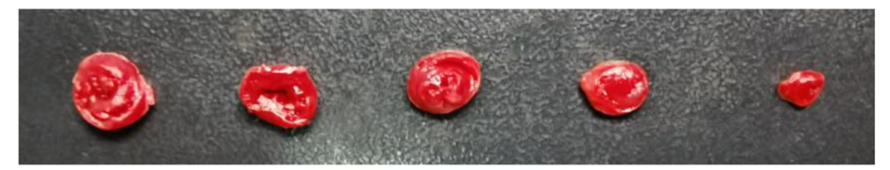

$\mathrm{I} / \mathrm{R}$

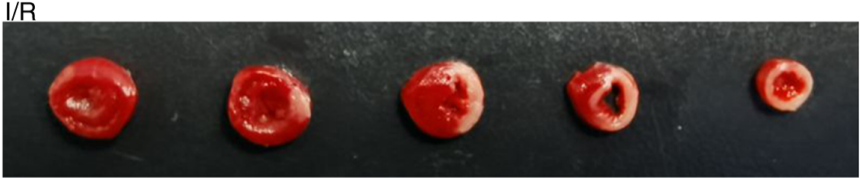

C

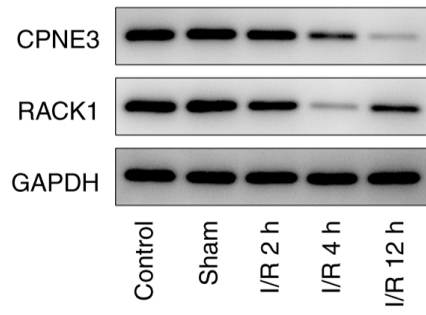

$\mathrm{I} / \mathrm{R}$
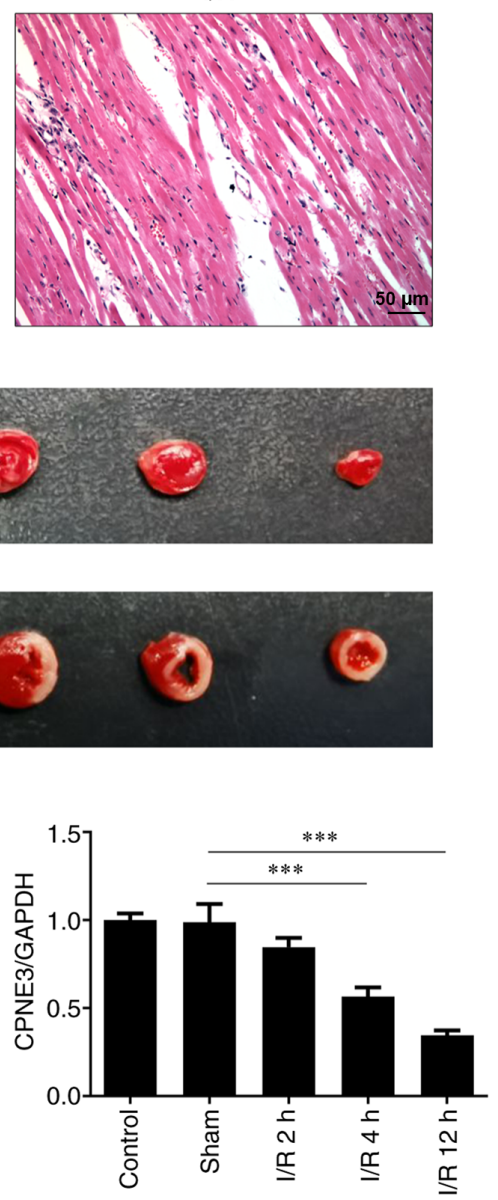
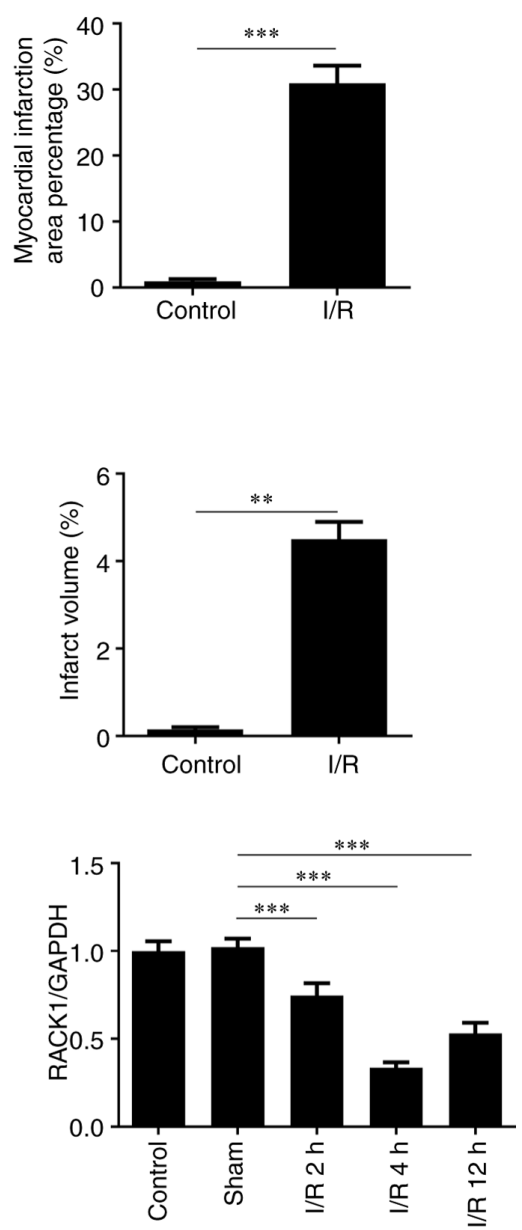
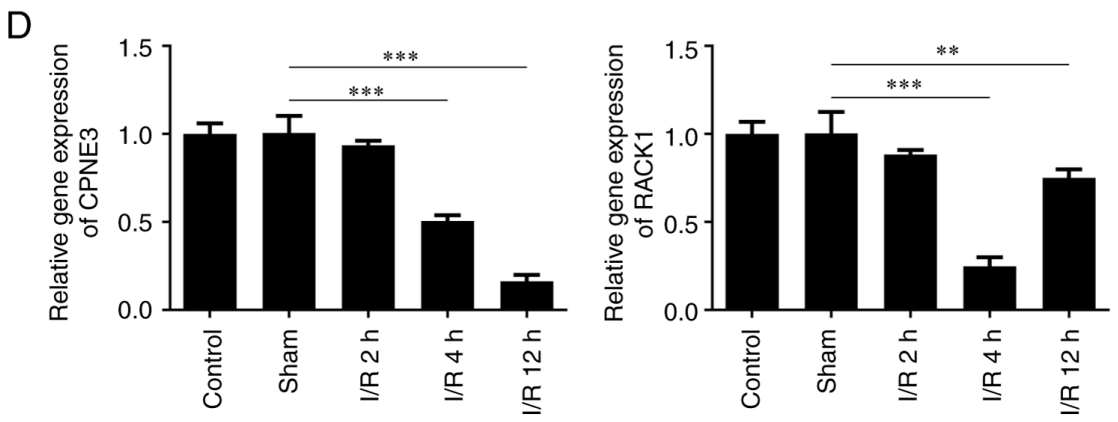

Figure 1. (A) H\&E staining was performed to assess pathological infiltration and ischemic areas of the myocardial tissues. (B) Tetrazolium chloride staining was used to detect the ischemic areas of the brain tissue. (C) Protein and (D) mRNA expression levels of CPNE3 and RACK1 in I/R-induced rat tissues. ${ }^{* *} \mathrm{P}<0.01,{ }^{* * *} \mathrm{P}<0.001$. CPNE3, copine 3; RACK1, receptor for activated C kinase $1 ; \mathrm{I} / \mathrm{R}$, ischemia/reperfusion.

CPNE3 overexpression activates RACK1 expression in $H / R$-induced cardiomyocytes. To investigate how CPNE3 affected or interacted with RACK1 in myocardial I/R injury, untreated $\mathrm{H} 9 \mathrm{c} 2$ cells and $\mathrm{H} 9 \mathrm{c} 2$ cells exposed to $4 \mathrm{~h}$ of $\mathrm{H} / \mathrm{R}$ were transfected with Ov-CPNE3. CPNE3 expression was detected via RT-qPCR and western blotting. The Ov-CPNE3 group displayed significantly increased CPNE3 expression levels compared with those in the Ov-NC group (Fig. 3A and B). Similarly, CPNE3 expression levels were significantly elevated in the H/R $4 \mathrm{~h}+\mathrm{Ov}-\mathrm{CPNE} 3$ group compared with those in the H/R $4 \mathrm{~h}+\mathrm{Ov}-\mathrm{NC}$ group (Fig. 3C and D). Subsequently, RT-qPCR and western blotting were performed to detect the expression levels of RACK1 in different groups. The results demonstrated that RACK1 expression was significantly decreased in the H/R $4 \mathrm{~h}$ group compared with that in the control group. Moreover, RACK1 expression was significantly increased in $\mathrm{H} 9 \mathrm{c} 2$ cells subjected to $\mathrm{H} / \mathrm{R}$ for $4 \mathrm{~h}$ that were transfected with Ov-CPNE3 compared with those transfected with Ov-NC (Fig. 3E and F). Furthermore, the IP assay results revealed that the relative enrichment of CPNE3 and RACK1 was statistically enhanced after treatment with the CPNE3 polyclonal antibody compared with that in the $\operatorname{IgG}$ group, which indicated the interaction between CPNE3 and RACK1 (Fig. 3G). Taken together, these results suggested that CPNE3 interacted with RACK1, and CPNE3 overexpression activated RACK1 expression in H9c2 cells induced by $4 \mathrm{~h}$ of H/R.

CPNE3 overexpression alleviates $H / R$-induced decreases in $H 9 c 2$ cell viability and inhibits $L D H$ cytotoxic release via RACK1 activation. To examine the potential effect of the 
A

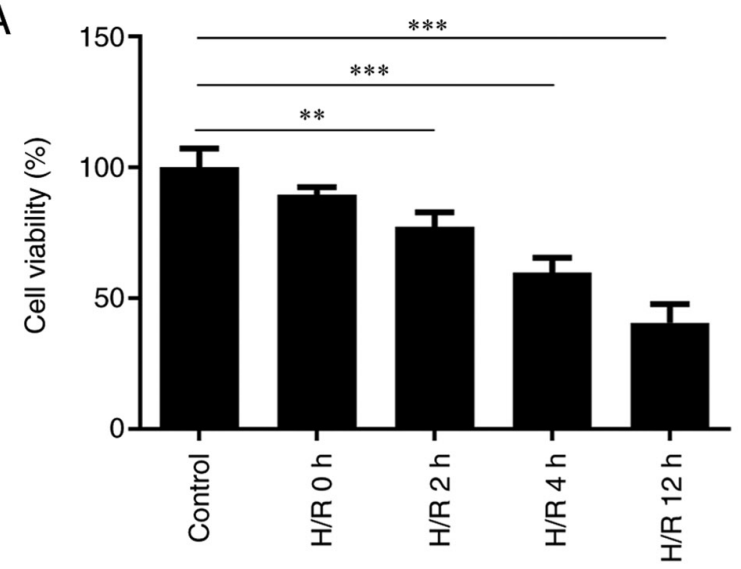

C

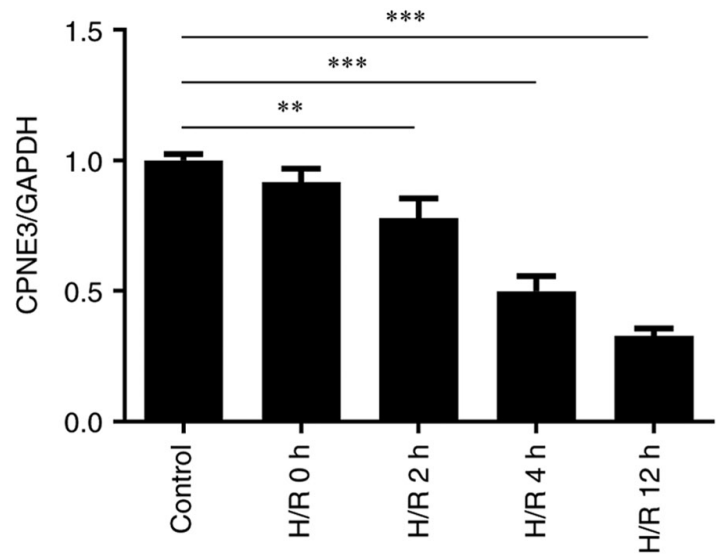

D

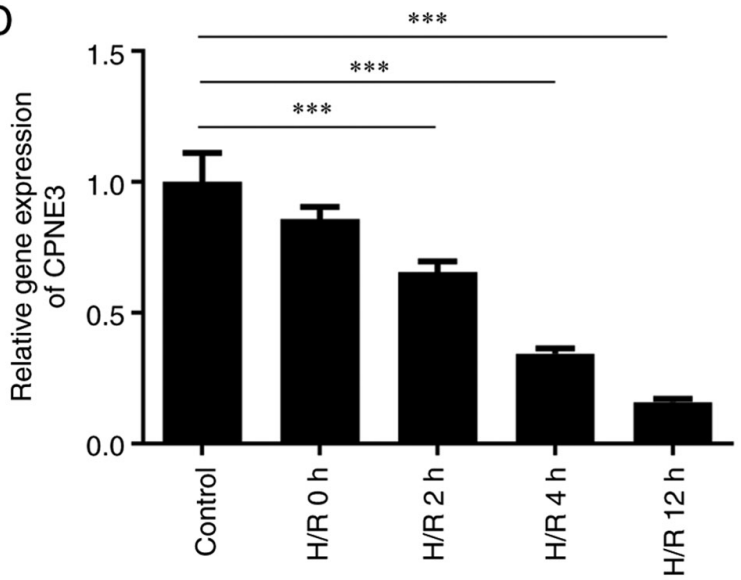

$\mathrm{B}$
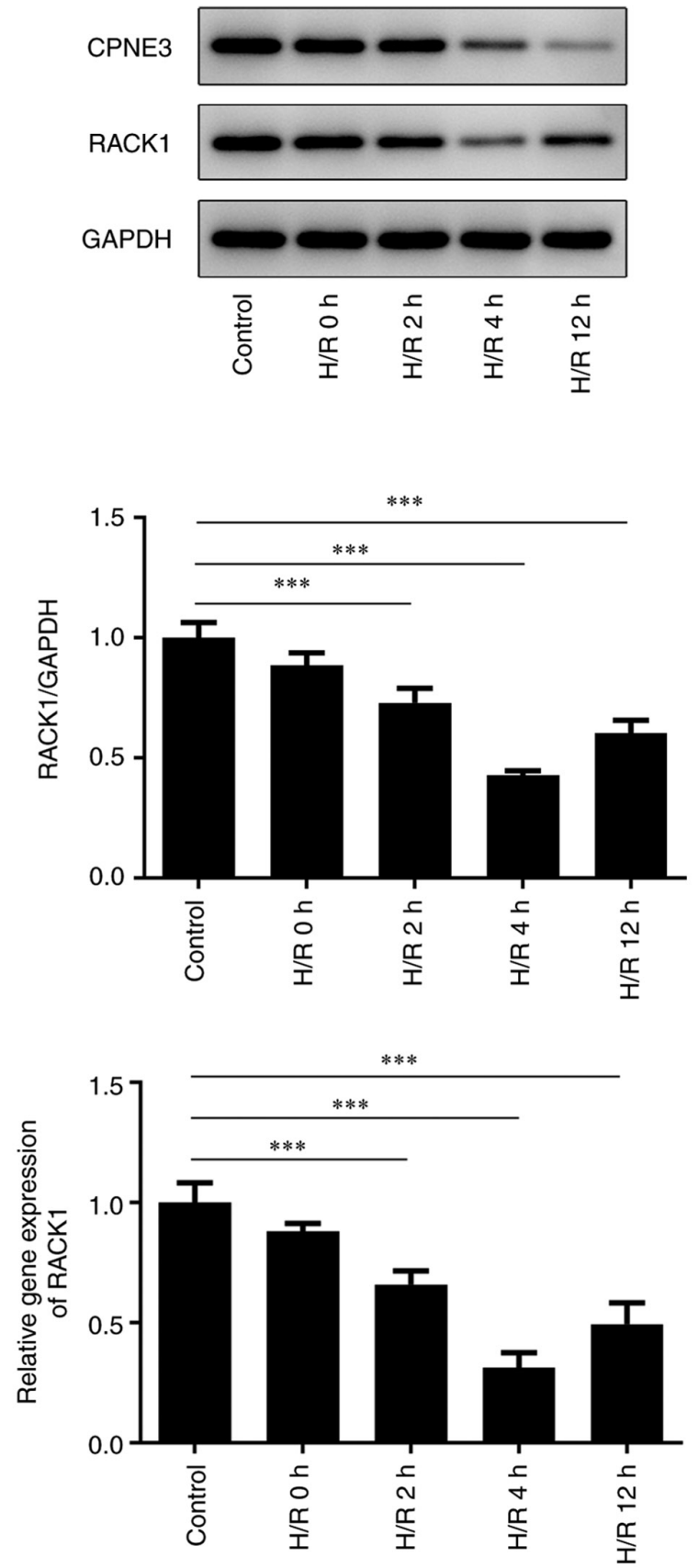

Figure 2. (A) H9c2 cell viability after H/R for $0,2,4$ or $12 \mathrm{~h}$ was detected by performing Cell Counting Kit-8 assays. CPNE3 and RACK1 protein expression levels in $\mathrm{H} 9 \mathrm{c} 2$ cells after $\mathrm{H} / \mathrm{R}$ for $0,2,4$ or $12 \mathrm{~h}$ were (B) determined by western blotting and (C) semi-quantified. (D) CPNE3 and RACK1 mRNA expression levels in $\mathrm{H} 9 \mathrm{c} 2$ cells after $\mathrm{H} / \mathrm{R}$ for $0,2,4$ or $12 \mathrm{~h} .{ }^{* * *} \mathrm{P}<0.01,{ }^{* * *} \mathrm{P}<0.001$. H/R, hypoxia/reoxygenation; CPNE3, copine 3; RACK1, receptor for activated $\mathrm{C}$ kinase 1 .

interaction between CPNE3 and RACK1, H9c2 cells were transfected with RACK1-targeted siRNAs. siRNA-RACK1-1 transfection resulted in the lowest expression levels of RACK1 compared with the siRNA-NC and siRNA-RACK1-2 groups (Fig. 4A and B). Thus, siRNA-RACK1-1 was selected for subsequent experiments. The viability of H/R-induced $\mathrm{H} 9 \mathrm{c} 2$ cells in different groups was assessed using a CCK-8 assay. Cell viability that was weakened by $H / R$ for $4 \mathrm{~h}$ was significantly enhanced by CPNE3 overexpression. Furthermore, siRNA-RACK1 significantly downregulated the viability of H/R-induced H9c2 cells co-transfected with Ov-CPNE3 compared with those co-transfected with siRNA-NC (Fig. 4C).
The release of cytotoxic LDH in H/R-induced H9c2 cells was assessed using a LDH detecting commercial kit. It was found that, compared with the control group, $4 \mathrm{~h}$ of $\mathrm{H} / \mathrm{R}$ significantly increased the release of LDH in $\mathrm{H} 9 \mathrm{c} 2$ cells, which was significantly decreased by CPNE3 overexpression. However, CPNE3 overexpression-induced effects on LDH release were significantly inhibited in $\mathrm{H} / \mathrm{R}$-induced $\mathrm{H} 9 \mathrm{c} 2$ cells co-transfected with siRNA-RACK1 compared with those co-transfected with siRNA-NC (Fig. 4D). These findings indicated that CPNE3 overexpression alleviated H/R-induced decreases in $\mathrm{H} 9 \mathrm{c} 2$ cell viability and inhibited the release of cytotoxic LDH by activating RACK1 expression. 
A

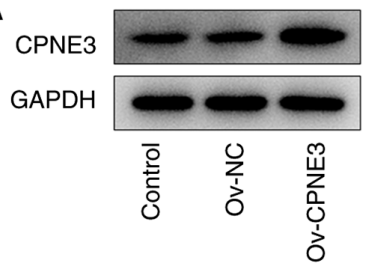

$\mathrm{C}$

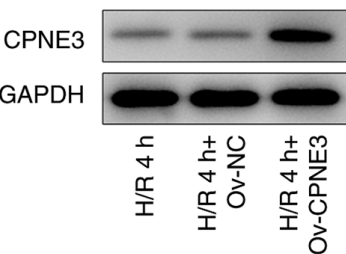

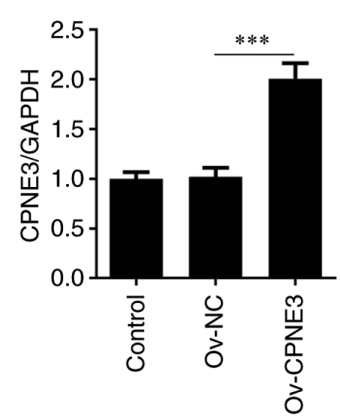

$\mathrm{E}$
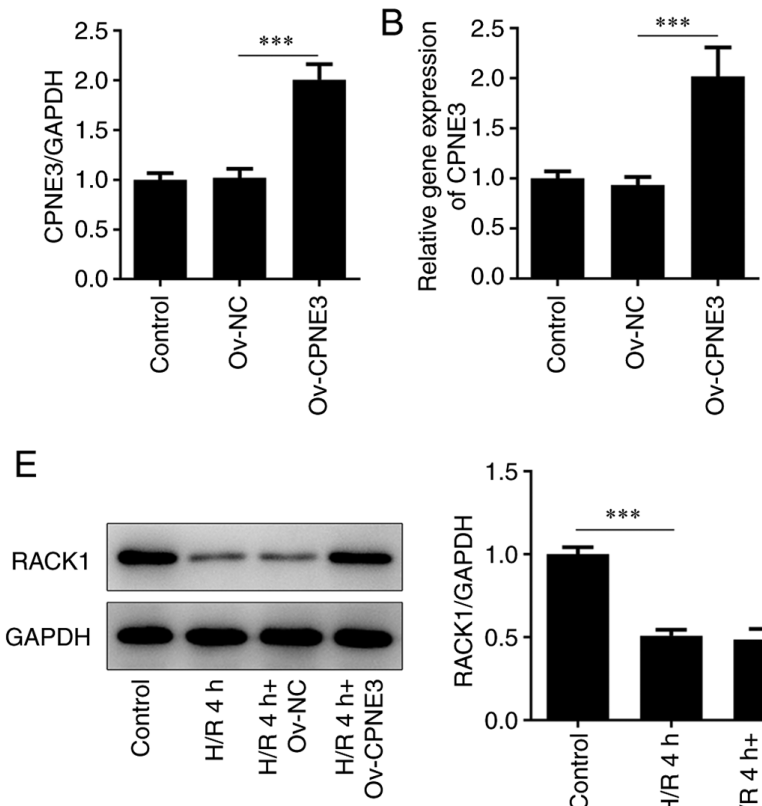

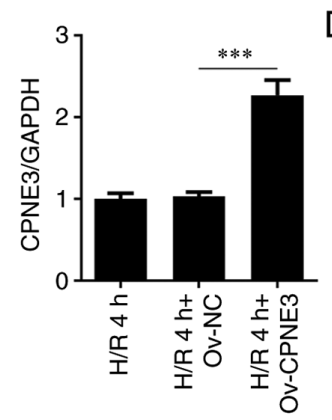

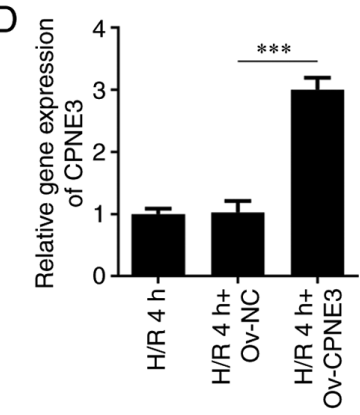
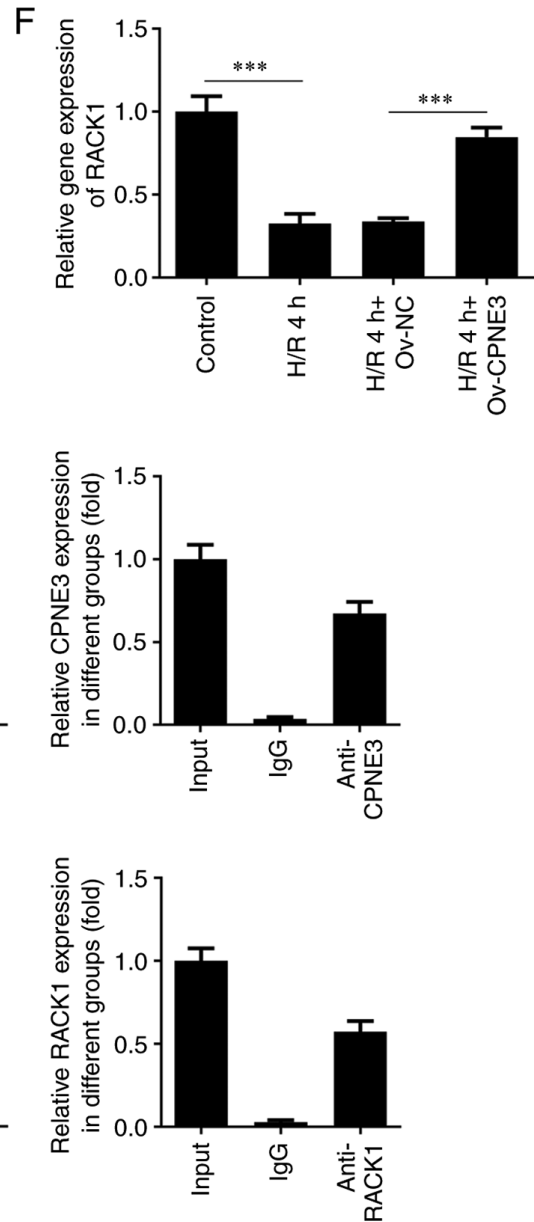

Figure 3. Transfection efficiency of Ov-CPNE3 was detected by (A) western blotting and (B) RT-qPCR. CPNE3 expression in H/R-induced H9c2 cell after transfection with Ov-CPNE3 was detected by (C) western blotting and (D) RT-qPCR. RACK1 expression in H/R-induced H9c2 cells after transfection with Ov-CPNE3 overexpression plasmid was detected by (E) western blotting and (F) RT-qPCR. (G) Relative enrichment of CPNE3 and RACK1 in H/R-induced $\mathrm{H} 9 \mathrm{c} 2$ treated with anti-CPNE3 was detected by performing an immunoprecipitation assay. ${ }^{* * *} \mathrm{P}<0.001$. Ov, overexpression; CPNE3, copine 3; RT-qPCR, reverse transcription-quantitative PCR; H/R, hypoxia/reoxygenation; RACK1, receptor for activated C kinase 1; NC, negative control.

$C P N E 3$ overexpression reduces the release of inflammatory cytokines in $H / R$-induced $H 9 c 2$ cells via RACK1 activation. To evaluate whether CPNE3 exerted an anti-inflammatory effect in myocardial I/R injury by interacting with RACK1, the expression levels of inflammatory response-related cytokines (TNF- $\alpha$, IL-1 $\beta$ and IL-6) in different treatment groups were detected via RT-qPCR and the expression levels of proinflammatory factors (p-NF- $\kappa$ B P65, P65 and Cox2) were detected via western blotting. The relative gene expression levels of TNF- $\alpha$, IL-1 $\beta$ and IL- 6 were significantly increased by H/R compared with those in the control group. CPNE3 overexpression significantly attenuated these increased expression levels 
A

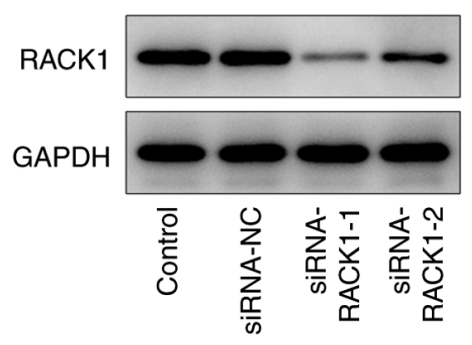

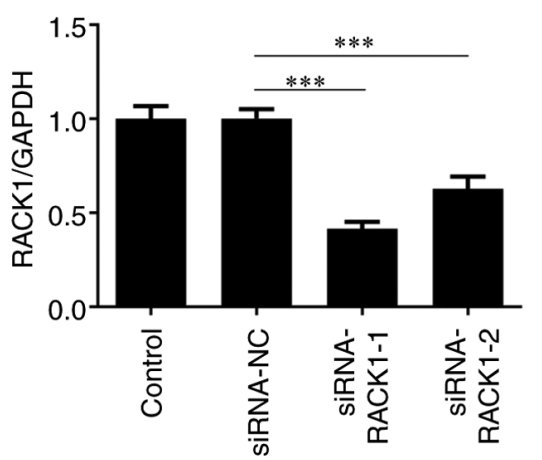

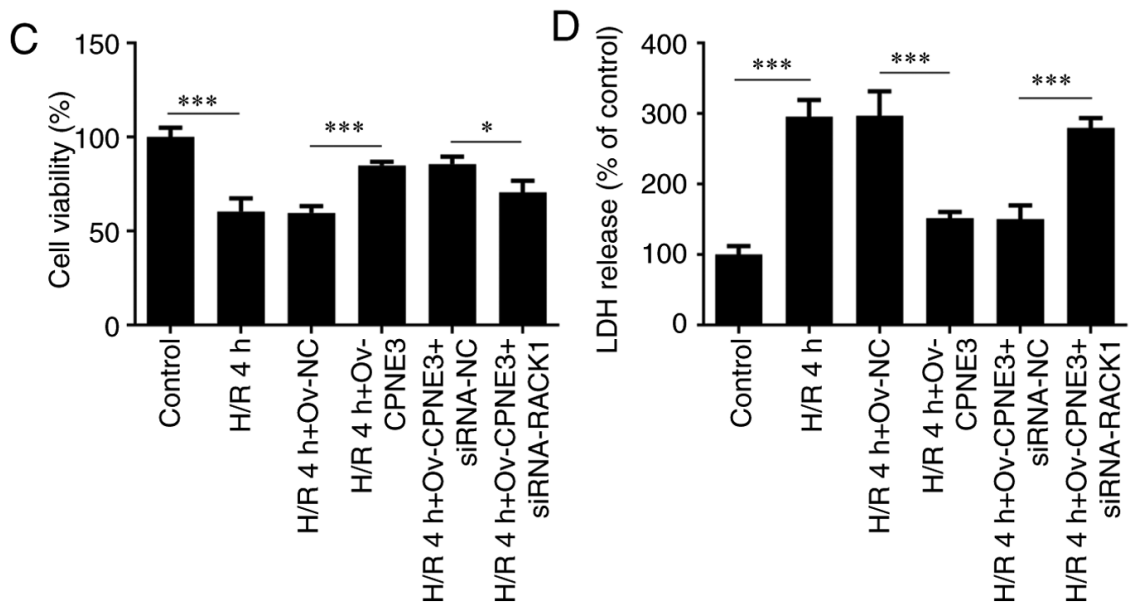

Figure 4. Transfection efficiencies of siRNA-RACK1-1 and siRNA-RACK1-2 in H9c2 cells were detected by (A) western blotting and (B) reverse transcription-quantitative PCR. (C) Effect of siRNA-RACK1 on H9c2 cell viability in H/R-induced, CPNE3-overexpressing H9c2 cells was detected by performing Cell Counting Kit-8 assays. (D) Effect of siRNA-RACK1 on LDH release in H/R-induced, CPNE3-overexpressing H9c2 cells was detected using an LDH assay kit. ${ }^{*} \mathrm{P}<0.05,{ }^{* * *} \mathrm{P}<0.001$. siRNA, small interfering RNA; RACK1, receptor for activated C kinase 1; H/R, hypoxia/reoxygenation; CPNE3, copine 3; LDH, lactate dehydrogenase; $\mathrm{NC}$, negative control; Ov, overexpression.

in H/R-induced H9c2 cells, an effect that was significantly inhibited by co-transfection with siRNA-RACK1 (Fig. 5A). The expression levels of $\mathrm{p}-\mathrm{NF}-\kappa \mathrm{B}$ P65/P65 and Cox 2 displayed similar trends; compared with the control group, the protein phosphorylation and expression levels, respectively, of these proinflammatory factors were significantly elevated by H/R. CPNE3 overexpression significantly attenuated these effects in H/R-induced H9c2 cells, whereas interference with siRNA-RACK1 significantly inhibited the effect of CPNE3 overexpression (Fig. 5B). These findings indicated that CPNE3 overexpression decreased the release of inflammatory cytokines in H/R-induced H9c2 cells by upregulating RACK1 expression.

CPNE3 overexpression decreases the apoptosis of $H / R$-induced H9c2 cells via RACK1 activation. To further investigate the effect induced by the interaction between CPNE3 and RACK1, cell apoptosis was assessed via TUNEL staining and western blotting. A significantly increased number of apoptotic cells was observed in the H/R group compared with that in the control group. A significant decrease in the number of apoptotic cells was identified after CPNE3 overexpression in H/R-induced H9c2 cells, whereas siRNA-RACK1 co-transfection significantly inhibited this effect (Fig. 6A and B). Moreover, the expression levels of the apoptosis-related proteins Bax, cleaved caspase- 3 and cleaved PARP were significantly elevated in the H/R $4 \mathrm{~h}$ group compared with those in the control group. However, H/R-induced effects on apoptosis-related protein expression levels were significantly decreased by CPNE3 overexpression. By contrast, siRNA-RACK1 significantly increased these expression levels in $\mathrm{H} / \mathrm{R}$-induced $\mathrm{H} 9 \mathrm{c} 2$ cells co-transfected with Ov-CPNE3 (Fig. 6C). Bcl-2 expression displayed the opposite trend. Moreover, total caspase-3 and PARP expression levels were not markedly altered among the groups. These results suggested that CPNE3 overexpression facilitated the decline in $\mathrm{H} / \mathrm{R}$-induced $\mathrm{H} 9 \mathrm{c} 2$ cell apoptosis by activating RACK1 expression.

\section{Discussion}

Reperfusion therapy is a typical approach used for the restoration of blood and oxygen supply to ischemic tissues, and is widely used in the treatment of acute myocardial infarction, pulmonary embolism, deep vein thrombosis and peripheral artery disease (8). Unfortunately, I/R has some negative side effects, resulting in severe dysfunction of the organism and even death (9). The pathological mechanism underlying I/R injury is often characterized by inflammation, abnormal microvascular function and cell death (10). A previous review described hyperbaric oxygen therapy as a protective strategy against I/R injury (11). Therefore, the present study established I/R-induced H9c2 cells to generate an in vitro myocardial ischemia-reperfusion injury model. The H9c2 cell line has the 
A

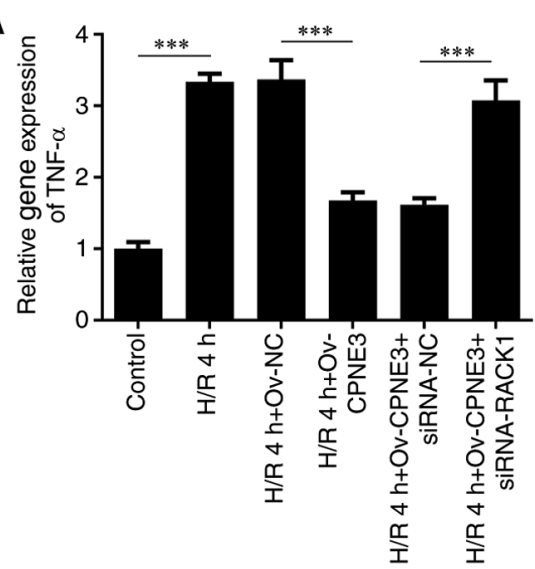

$\mathrm{B}$

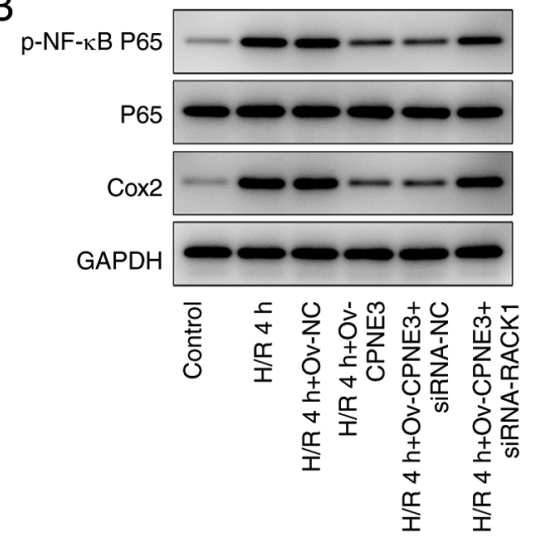

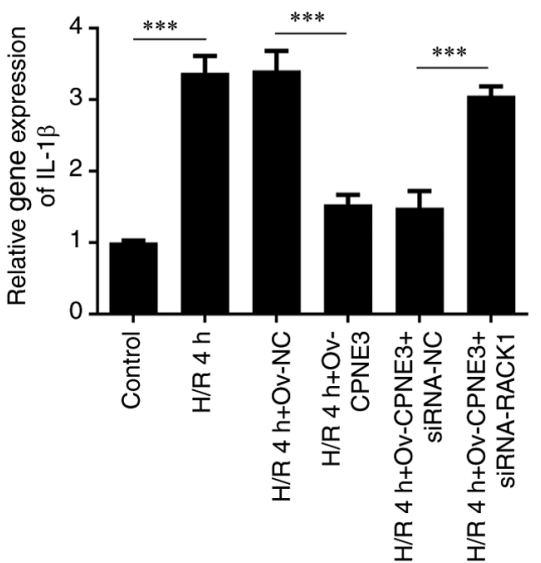
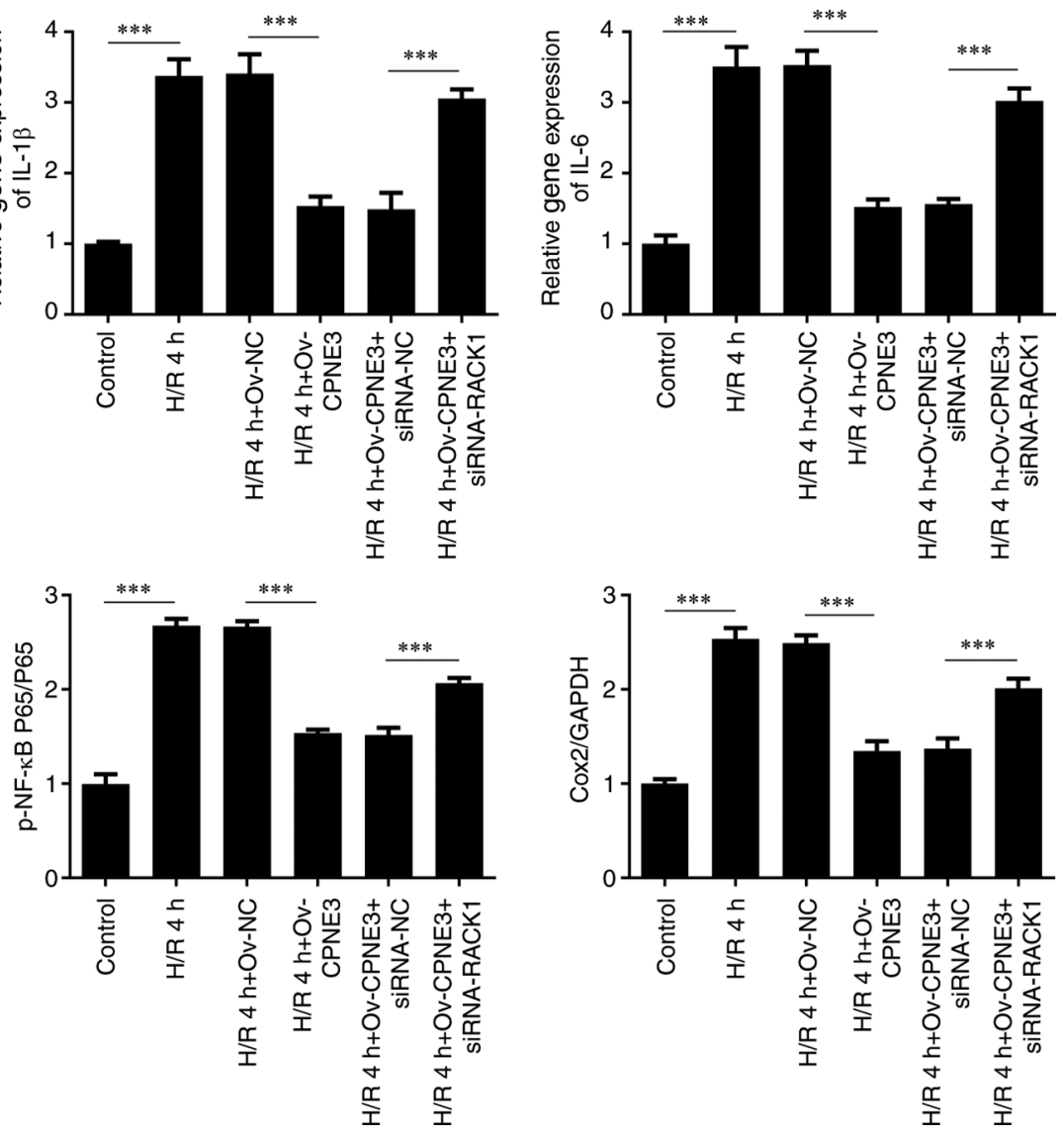

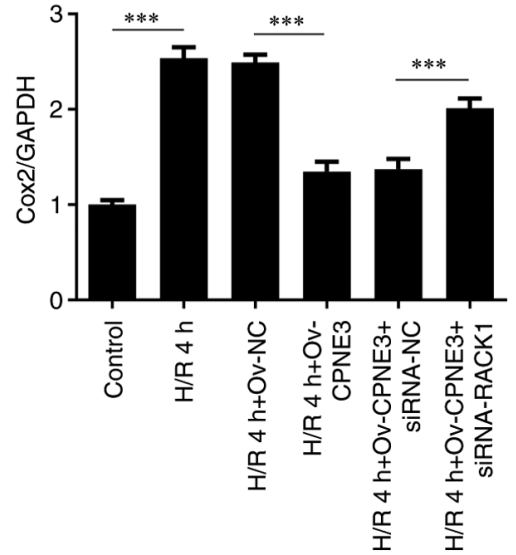

Figure 5. (A) Expression levels of TNF- $\alpha$, IL-1 $\beta$ and IL-6 in H/R-induced, CPNE3-overexpressing H9c2 cells co-transfected with siRNA-RACK1 were detected by reverse transcription-quantitative PCR. (B) Expression levels of p-NF- $\mathrm{B}$ P65, P65 and Cox 2 in H/R-induced, CPNE3-overexpressing H9c2 cells co-transfected with siRNA-RACK1 were detected by western blotting. ${ }^{*}{ }^{* *} \mathrm{P}<0.001$. H/R, hypoxia/reoxygenation; CPNE3, copine 3 ; siRNA, small interfering RNA; RACK1, receptor for activated C kinase 1; p, phosphorylated; NC, negative control; Ov, overexpression.

ability of cell division, and numerous studies have used $\mathrm{H} / \mathrm{R}$ to induce $\mathrm{H} 9 \mathrm{c} 2$ cells to establish myocardial ischemia injury model (12-14). In addition, due to the weak proliferative ability of primary cardiomyocytes (generally considered as telophase cells), the survival rate of primary cardiomyocytes is not high and the culture is difficult. Therefore, the present study used H9c2 cells to conduct the experiments. Future studies should verify the results of the present study in primary cardiomyocytes.

As previously mentioned, it has been shown that CPNE3 expression is closely associated with the risk of experiencing acute myocardial infarction that requires reperfusion therapy, and there is novel evidence that supports the interaction between CPNE3 and RACK1 in NSCLC (4). Therefore, the present study aimed to investigate the possible protective effect of CPNE on I/R injury via an interaction with RACK1. It has been reported that upregulation of CPNE3 suppresses the proliferation of glioblastoma cells via focal adhesion kinase signaling pathway inactivation (15). These results indicated that CPNE3 may serve an important regulatory effect in cell apoptosis. In addition, according to previous research, the expression level of RACK1 is downregulated after myocardial I/R and is closely associated with the apoptosis of cardiomyocytes (5). The experimental I/R injury rat model established in the present study showed consistent results with the aforementioned previous research, displaying significantly downregulated CPNE3 and RACK1 expression levels after I/R induction. Moreover, upregulated expression levels of RACK1 were observed in H/R-induced $\mathrm{H} 9 \mathrm{c} 2$ cells after transfection with Ov-CPNE3, and the IP assay results further validated the interaction between CPNE3 and RACK1.

The pathology underlying I/R injury can be partially represented by decreased cell viability, as a previous study has shown that thrombolysis and recanalization therapies on patients with acute ischemic stroke induce rapid loss of cell viability in the tissues (16). Therefore, the present study examined cell viability in H/R-induced H9c2 cells to assess the effect of CPNE3 interacting with RACK1. The results of the present study demonstrated that CPNE3 overexpression increased cell viability via RACK1 activation. Reperfusion therapy affects cell viability and causes cell death, largely due to being a toxic process itself (17). Moreover, the release of $\mathrm{LDH}$ is implicated in the $\mathrm{I} / \mathrm{R}$ process and is reported to be dependent on the duration of I/R (18). The present study demonstrated that CPNE3 overexpression could effectively inhibit the release of cytotoxic LDH by regulating RACK1 expression, which further indicated the potential role of CPNE3 in I/R injury.

$\mathrm{I} / \mathrm{R}$ therapy can contribute to or is not sufficient to overcome the inflammatory cascade in patients with atherosclerotic cardiovascular disease (19). A previous study 
A

Control

$\mathrm{H} / \mathrm{R} 4 \mathrm{~h}$
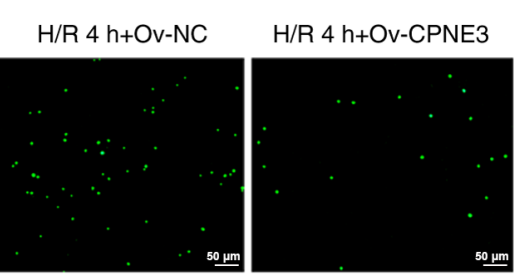

$\mathrm{H} / \mathrm{R} 4 \mathrm{~h}+\mathrm{OV}-\mathrm{CPNE} 3+\mathrm{H} / \mathrm{R} 4 \mathrm{~h}+\mathrm{Ov}-\mathrm{CPNE} 3+$
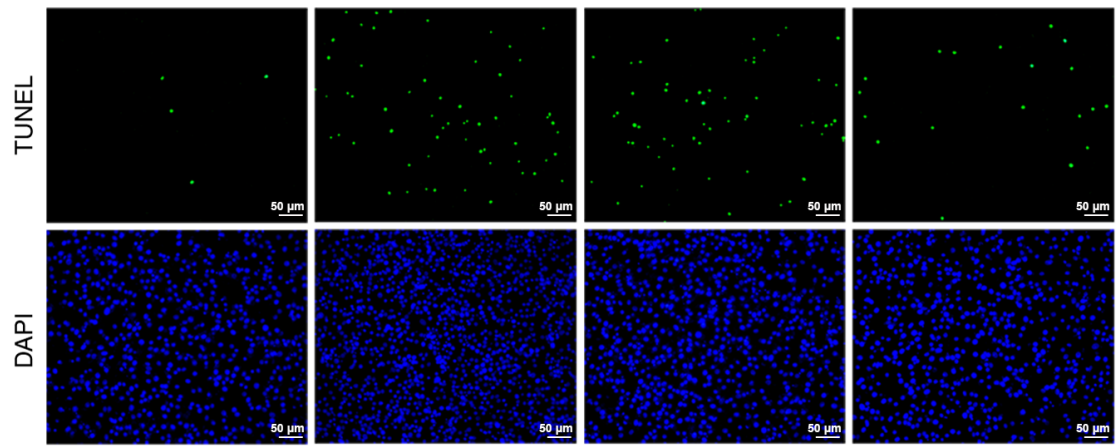
SiRNA-NC

SIRNA-RACK1
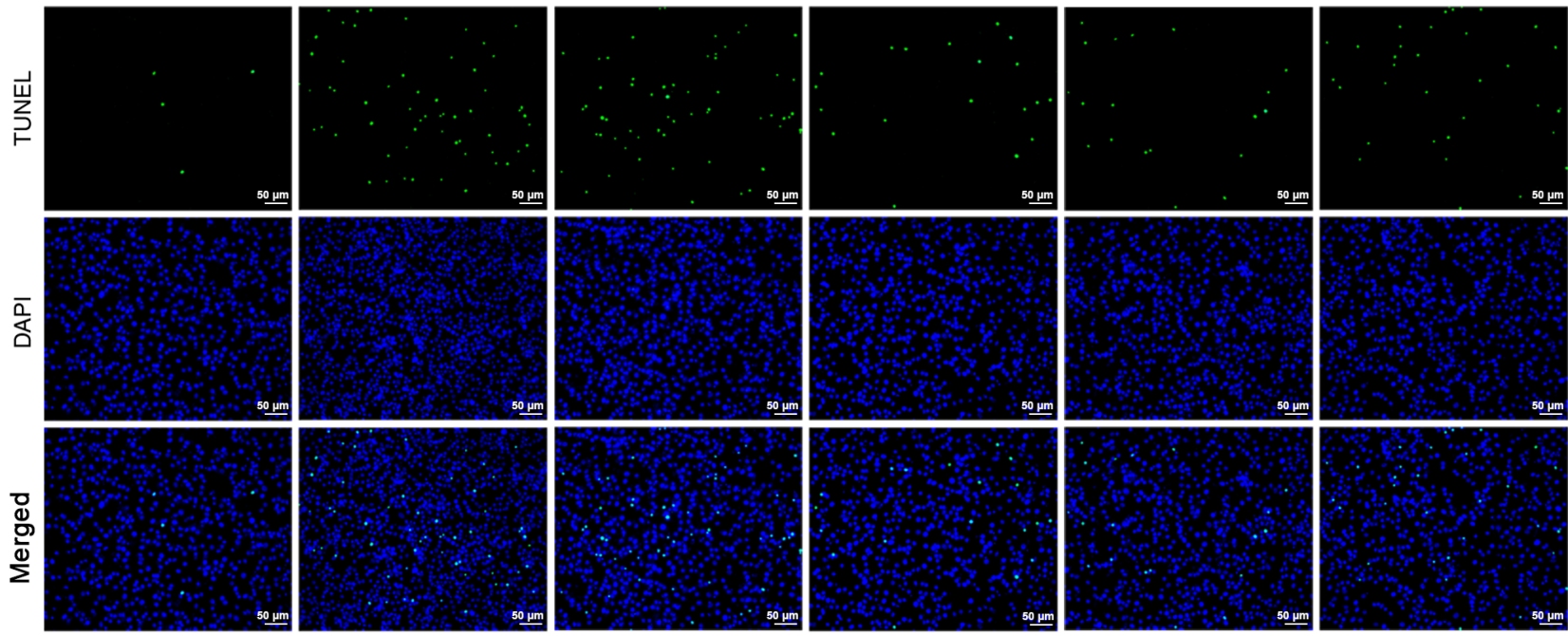

B
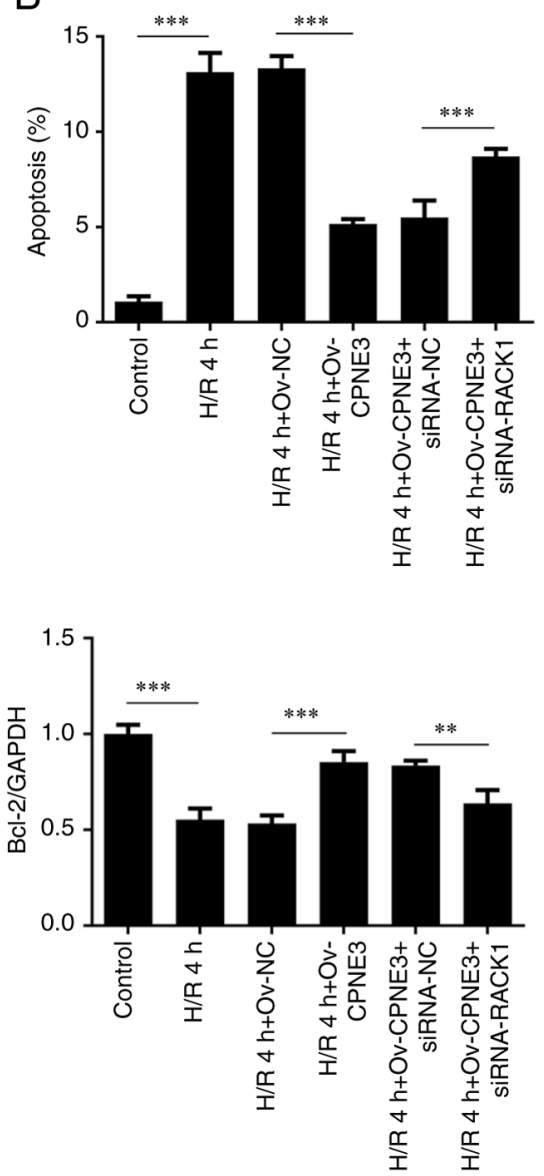

C
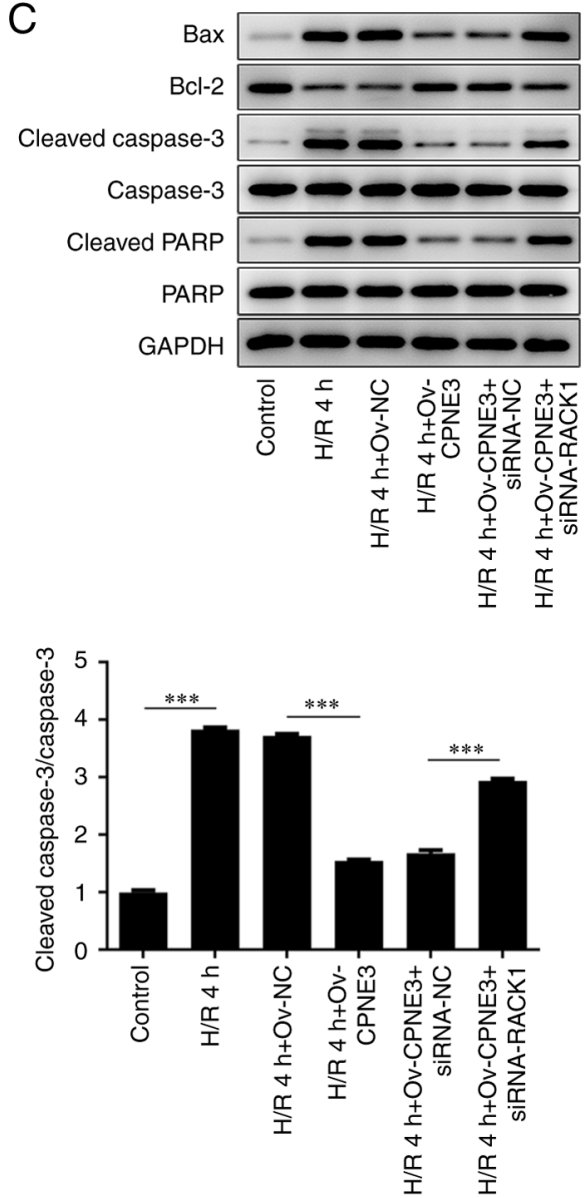
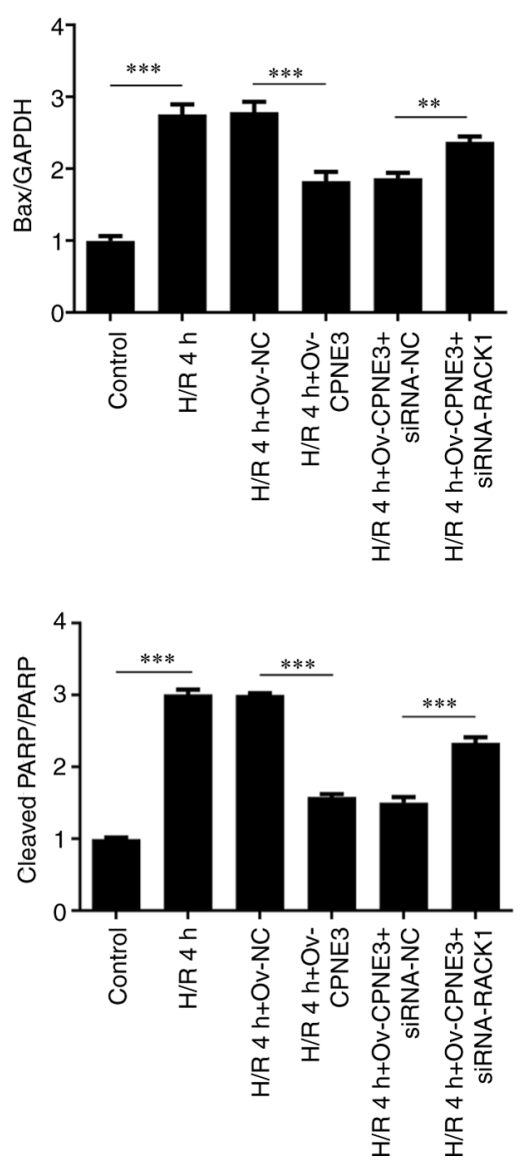

Figure 6. H9c2 cell apoptosis was (A) detected by performing TUNEL staining assays and (B) quantified. (C) Expression levels of apoptosis-related proteins in $\mathrm{H} 9 \mathrm{c} 2$ cells were detected by western blotting. ${ }^{* *} \mathrm{P}<0.01,{ }^{* * *} \mathrm{P}<0.001$. H/R, hypoxia/reoxygenation; Ov, overexpression; NC, negative control; siRNA, small interfering RNA; CPNE3, copine 3; RACK1, receptor for activated C kinase 1; PARP, poly(ADP-ribose) polymerase.

revealed that inhibiting the inflammatory response at the stage of early reperfusion may serve as a feasible strategy to prevent injury (20). The present study not only demonstrated an increased release of proinflammatory cytokines in H/R-induced H9c2 cells, but also confirmed the anti-inflammatory effect of CPNE3 on I/R injury by activating RACK1 expression. Signs of cell death are observed in patients after post-ischemic reperfusion, and such a tendency is difficult to alleviate $(21,22)$. I/R-induced apoptosis is considered a trigger for ultimate cell death (23). The level of apoptosis and the expression levels of apoptosis-related proteins were detected in the present study. An overall decline in cell apoptosis and the expression of apoptosis-related proteins was observed in H/R-induced H9c2 cells following transfection with 
Ov-CPNE3, and Ov-CPNE3-mediated effects were inhibited by siRNA-RACK1 interference. Thus, the results suggested that the interaction between CPNE3 and RACK1 regulated cardiomyocyte apoptosis.

Collectively, the present study suggested that CPNE3 may serve an important role in preventing $\mathrm{I} / \mathrm{R}$ injury by interacting with RACK1. Therefore, the results of the present study may facilitate the development of advanced preventive strategies against myocardial I/R injury and novel clinical therapeutic strategies for patients with $\mathrm{I} / \mathrm{R}$.

\section{Acknowledgements}

Not applicable.

\section{Funding}

No funding was received.

\section{Availability of data and materials}

The datasets used and/or analyzed generated during the current study are available from the corresponding author on reasonable request.

\section{Authors' contributions}

$\mathrm{XZ}$ wrote the manuscript and analyzed the data. $\mathrm{XH}$ and $\mathrm{YZ}$ carried out the experiments, supervised the present study, searched the literature and revised the manuscript. All authors read and approved the final manuscript. XZ and XH confirm the authenticity of all the raw data.

\section{Ethics approval and consent to participate}

The present study was approved by the Committee on the Ethics of Animal Experiments of Cangzhou Central Hospital. All animal experiments comply with the ethical requirements of the animal council.

\section{Patient consent for publication}

Not applicable.

\section{Competing interests}

The authors declare that they have no competing interests.

\section{References}

1. Binder A, Ali A, Chawla R, Aziz HA, Abbate A and Jovin IS Myocardial protection from ischemia-reperfusion injury post coronary revascularization. Expert Rev Cardiovasc Ther 13: $1045-1057,2015$

2. Tan B, Liu L, Yang Y, Liu Q, Yang L and Meng F: Low CPNE3 expression is associated with risk of acute myocardial infarction: A feasible genetic marker of acute myocardial infarction in patients with stable coronary artery disease. Cardiol J 26: 186-193, 2019.

3. Katanasaka Y: Development of targeted pharmacotherapy for cardiovascular disease. Yakugaku Zasshi 137: 1349-1353, 2017 (In Japanese).
4. Lin H, Zhang X, Liao L, Yu T, Li J, Pan H, Liu L, Kong H, Sun L, Yan $M$ and Yao M: CPNE3 promotes migration and invasion in non-small cell lung cancer by interacting with RACK1 via FAK signaling activation. J Cancer 9: 4215-4222, 2018.

5. Willerson JT, Watson JT, Hutton I, Fixler DE, Curry GC and Templeton GH: The influence of hypertonic mannitol on regional myocardial blood flow during acute and chronic myocardial ischemia in anesthetized and awake intact dogs. J Clin Invest 55: 892-902, 1975.

6. Qian L, Shi J, Zhang C, Lu J, Lu X, Wu K, Yang C, Yan D, Zhang C, You Q and Liu X: Downregulation of RACK1 is associated with cardiomyocyte apoptosis after myocardial ischemia/reperfusion injury in adult rats. In Vitro Cell Dev Biol Anim 52: 305-313, 2016.

7. Livak KJ and Schmittgen TD: Analysis of relative gene expression data using real-time quantitative PCR and the 2(-Delta Delta C(T)) method. Methods 25: 402-408, 2001.

8. Bhaskar S, Stanwell P, Cordato D, Attia J and Levi C: Reperfusion therapy in acute ischemic stroke: Dawn of a new era? BMC Neurol 18: 8, 2018.

9. Kalogeris T, Baines CP, Krenz $\mathrm{M}$ and Korthuis RJ: Ischemia/Reperfusion. Compr Physiol 7: 113-170, 2016.

10. Granger DN and Kvietys PR: Reperfusion therapy-What's with the obstructed, leaky and broken capillaries? Pathophysiology 24: 213-228, 2017.

11. Hentia C, Rizzato A, Camporesi E, Yang Z, Muntean DM, Săndesc D and Bosco G: An overview of protective strategies against ischemia/reperfusion injury: The role of hyperbaric oxygen preconditioning. Brain Behav 8: e00959, 2018.

12. Ma K, Qiu J, Zhou M, Yang Y and Ye X: Cox-2 negatively affects the protective role of propofol against hypoxia/reoxygenation induced cardiomyocytes apoptosis through suppressing akt signaling. Biomed Res Int 2019: 7587451, 2019.

13. Ge L, Cai Y, Ying F, Liu H, Zhang D, He Y, Pang L, Yan D, $\mathrm{Xu} \mathrm{A}, \mathrm{Ma} \mathrm{H}$ and Xia Z: MiR-181c-5p exacerbates hypoxia/reoxygenation-induced cardiomyocyte apoptosis via targeting PTPN4. Oxid Med Cell Longev 2019: 1957920, 2019.

14. He F, Wu Q, Xu B, Wang X, Wu J, Huang L and Cheng J: Suppression of Stim1 reduced intracellular calcium concentration and attenuated hypoxia/reoxygenation induced apoptosis in H9C2 cells. Biosci Rep 37: BSR20171249, 2017.

15. Shi D, Lin B, Lai J, Li K and Feng Y: Upregulation of CPNE3 suppresses invasion, migration and proliferation of glioblastoma cells through FAK pathway inactivation. J Mol Histol 52: 589-596, 2021.

16. Carati CJ, Rambaldo S and Gannon BJ: Changes in macromolecular permeability of microvessels in rat small intestine after total occlusion ischemia/reperfusion. Microcirc Endothelium Lymphatics 4: 69-86, 1988.

17. Hacker TA, Diarra G, Fahl BL, Back S, Kaufmann E and Fahl WE: Significant reduction of ischemia-reperfusion cell death in mouse myocardial infarcts using the immediate-acting PrC-210 ROS-scavenger. Pharmacol Res Perspect 7: e00500, 2019.

18. Rossello X, Hall AR, Bell RM and Yellon DM: Characterization of the langendorff perfused isolated mouse heart model of global ischemia-reperfusion injury: Impact of ischemia and reperfusion length on infarct size and LDH release. J Cardiovasc Pharmacol Ther 21: 286-295, 2016.

19. Goldfine AB and Shoelson SE: Therapeutic approaches targeting inflammation for diabetes and associated cardiovascular risk. J Clin Invest 127: 83-93, 2017.

20. Bonaventura A, Montecucco F and Dallegri F: Cellular recruitment in myocardial ischaemia/reperfusion injury. Eur J Clin Invest 46: 590-601, 2016.

21. Heusch G: Critical issues for the translation of cardioprotection. Circ Res 120: 1477-1486, 2017.

22. Hausenloy DJ and Yellon DM: Ischaemic conditioning and reperfusion injury. Nat Rev Cardiol 13: 193-209, 2016.

23. Jiang X, Lew KS, Chen Q, Richards AM and Wang P: Human mesenchymal stem cell-derived exosomes reduce ischemia/reperfusion injury by the inhibitions of apoptosis and autophagy. Curr Pharm Des 24: 5334-5341, 2018.

This work is licensed under a Creative Commons Attribution-NonCommercial-NoDerivatives 4.0 International (CC BY-NC-ND 4.0) License. 